\title{
Morphological contrast and merger: ranuki in Japanese*
}

\author{
Junko Ito and Armin Mester \\ University of California, Santa Cruz \\ August 2004
}

\section{Introduction}

The central notion of structural linguistics is that of contrast or opposition: The linguistic value and role of a unit cannot be reduced to its physical substance, but is crucially determined by the network of relations that it enters into with other units of a similar kind: phoneme to phoneme, morpheme to morpheme, etc. A mid front vowel /e/ in a five-vowel system is something quite different from an /e/ in a seven-vowel system, perfect tense in a system without imperfect is something different from perfect tense in a system with imperfect, etc. Structuralist phonemics is the embodiment of a theory built on contrast as a central notion.

Generative phonology, on the other hand, was virtually founded on the rejection of a strictly phonemic level of representation where all and only the contrastive units of a sound system are represented (Halle 1962). The focus was instead on the new device of the phonological derivation, with a sequence of phonological rules deriving phonetic output representations from abstract morphophonemic inputs. Neither of these two levels served as a representation of contrastive function in the sense of structuralist phonemics, and there was also no formal separation into rules neutralizing contrasts between phonemes and rules deriving allophones. All in all, classical generative phonology had little use for contrast as an operative element of the theory, and the notion was perceived as functionalist and unfit for the rigors of formal analysis. ${ }^{1}$

Recent work has seen an impressive re-emergence of contrast as a key element of phonological theory and analysis. Within OT Phonology, the work of Flemming 1995, 2002 and Padgett 2003, showed that considerations of contrastive function need not remain at the level of vague appeals to trends and tendencies, but can be given a precise formal expression that is fully integrated with the rest of the grammar.

The purpose of this note is to take up an example of a contrast-effect in morphology from Japanese, the so-called ra-dropping or ra-nuki (ら抜き, lit. 'ra-pullout') in the potential form of

\footnotetext{
* We are grateful to Haruo Kubozono, Jaye Padgett, John Whitman, and an anonymous reviewer for useful suggestions, as well as to audiences at the 2003 Phonology Forum (Kobe College) and at colloquia at UC Santa Cruz and at Cornell University.

${ }^{1}$ Every descriptively adequate theory of phonology needs a way of distinguishing contrasting segments from non-contrasting pairs of segments. In the further development of generative phonology, this task fell to underspecification, with non-contrastive features being left out in underlying representations and filled in by rule in the course of the derivation.

Underspecification has been found to have fundamental problems and paradoxes (see McCarthy and Taub 1992 and Steriade 1995) and has been largely abandoned in OT (see Smolensky 1993 and subsequent work for arguments).
} 
verbs with vowel-final stems. After a brief review of contrast-based OT phonology, we proceed to demonstrate that very similar considerations play an important role in morphology, where they can be given a parallel formal analysis. ${ }^{2}$

\section{Contrast in OT Phonology}

The contrast-based version of OT employed here (1) is taken from Ito and Mester to appear, which is in turn based on Padgett 2003.

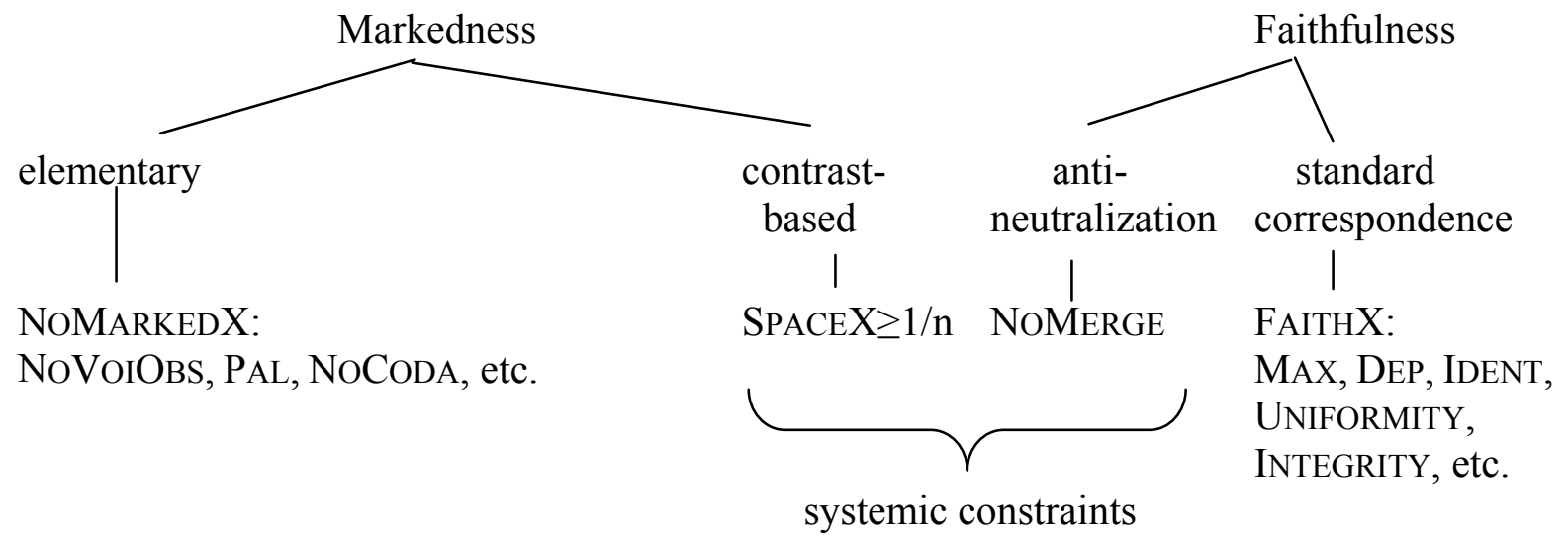

Here both the markedness and the faithfulness component of OT are enriched by systemic constraints, which are further characterized in (2) (see the works cited for discussion).

(2) Systemic markedness and systemic faithfulness constraints

\begin{tabular}{|l|l|l|}
\hline $\begin{array}{l}\text { Systemic } \\
\text { Markedness: }\end{array}$ & SPACEX $\geq 1 / \mathrm{n}$ & $\begin{array}{l}\text { Potential minimal pairs differing in property X must differ } \\
\text { in X by at least } 1 / \text { nth of the available space }\end{array}$ \\
\hline $\begin{array}{l}\text { Systemic } \\
\text { Faithfulness: }\end{array}$ & NOMERGE & $\begin{array}{l}\text { No output word has multiple correspondents in the input } \\
\text { (cf. Uniformity) }\end{array}$ \\
\hline
\end{tabular}

Hand-in-hand with the development of systemic OT goes a broader conception of inputs and candidates. In order to bring merger of, and contrast between, distinct forms under the purview of formal optimality-theoretic evaluation, inputs and candidates cannot exclusively consist of isolated forms (or isolated input-output pairings, in correspondence theory). Rather, a whole group of related forms must be able to constitute an input and a candidate. Systemic OT is not alone in adopting this broader conception, which it shares, for example, with proposals to admit whole paradigms as objects of optimality-theoretic evaluation, as in McCarthy to appear. ${ }^{3}$

\footnotetext{
${ }^{2}$ In work in preparation, Shigeto Kawahara (UMass, Amherst) and Jaye Padgett (UC Santa Cruz) have independently developed a proposal along somewhat different though related lines. ${ }^{3}$ Note, for example, that because of the fluidity of the distinction between inflection and derivation and the fact that recursivity cannot be in principle ruled out, there is no known upper
} 
We illustrate systemic OT with a brief look at a contrast-enhancing depalatalization process in the historical phonology of Japanese analyzed in Ito and Mester to appear, where the sibilant [S] depalatalizes to [s] before the mid front vowel [e], as in (3)b. ${ }^{4}$

(3)

a. Older system

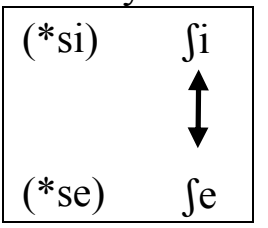

b. Modern system

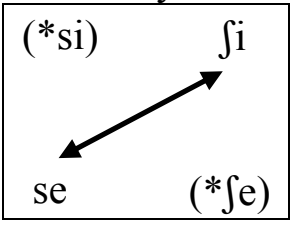

Depalatalization before [e] is baffling as a syntagmatic process since front vowels are wellknown triggers of palatalization in preceding coronals, especially in sibilants. But interpreted in a systemic way, the shift can be rationalized as a means of enhancing the contrast by polarizing the consonants. Overall, [ $\mathrm{ji} / \mathrm{se}]$ is a better contrast between moras than [ $\mathrm{Si} / \mathrm{Se}]$. Our analysis, summarized in (4), gives formal expression to this idea.

(4)

\begin{tabular}{|c|c|c|c|}
\hline \multicolumn{4}{|c|}{ a. Older ranking: } \\
\hline & 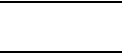 & PAL & $\mu$-CONTRAST \\
\hline & se ${ }^{\int i}$ & $* !$ & \\
\hline$\downarrow$ & $\begin{array}{l}\int \mathrm{di} \\
\mathrm{Se}\end{array}$ & & $*$ \\
\hline
\end{tabular}

b. Modern ranking:

\begin{tabular}{|l|l||l|l|}
\hline \multicolumn{2}{|l||}{} & $\mu$-CONTRAST & PAL \\
\hline \hline & se & & $*$ \\
& & & \\
\hline & $\int \mathrm{i}$ & $* !$ & \\
& & & \\
\hline
\end{tabular}

The spacing constraint $\mu$-CONTRAST is a paradigmatic markedness constraint declaring the contrast between two mora-sized items (here, [ $[\mathrm{i}]$ and $\left[\int \mathrm{e}\right]$ ) as insufficient if they are identical at their left edges and contrast only in their vowel quality [i] vs. [e]. Ranked above PAL, a constraint demanding palatalization of sibilants before all front vowels, it gives rise to the modern system.

\section{Contrast in Morphology: Verbal ranuki in Japanese}

The phenomenon commonly known as ranuki "ra-dropping" is illustrated in (5) where the potential suffix -rare is alternatively realized in a reduced form as -re by deleting the syllable $r a$. The $r a$-less forms are considered substandard in textbooks and prescriptive grammars.

limit on the size of a possible paradigm (except for the Guiness-book-of-records-fact that some paradigm in some language must be the longest known paradigm).

${ }^{4}$ In a more narrow transcription, many speakers have alveolo-palatal [c] rather than palatoalveolar [S], i.e., the segment in question is further back and involves more raising of the tongue. 
(5)
a.
kinoo-wa yoku ne- $\left\{\begin{array}{c}\text { rare } \\ \varnothing \text { re }\end{array}\right\} \quad$-ta
yesterday-TOPIC well sleep-POTENTIAL -PAST
'(I) was able to sleep well last night'
b. koko-kara-wa de- $\left\{\begin{array}{c}\text { rare } \\ \varnothing \text { re }\end{array}\right\} \quad$-mas-en
here-from-TOPIC exit-POTENTIAL -POLITE-NEGATIVE
'(You) cannot exit from here.'

We will develop an OT analysis of this phenomenon after a brief overview and preliminary considerations regarding allomorph selection.

\subsection{Allomorph selection}

Verbal stems in Japanese are divided into two classes: consonant-final C-stems and vowel-final V-stems. ${ }^{5}$ The latter always end in a final vowel [i] or [e].

(6)

\begin{tabular}{|llll|}
\hline V-stems & \multicolumn{3}{c|}{ C-stems } \\
\hline tabe- & 'eat' & hak- & 'sweep' \\
ne- & 'sleep' & oyog- & 'swim' \\
sabi- & 'get rusty' & kas- & 'lend' \\
ki- & 'wear' & yom- & 'read' \\
mi- & 'see' & sin- & 'die' \\
make- & 'lose' & tob- & 'fly' \\
kari- & 'borrow' & kaw- & 'buy' \\
home- & 'praise' & wakar- & 'understand' \\
\hline
\end{tabular}

Most verbal suffixes have different allomorphs that occur with C-stems and V-stems, respectively (7).

(7) Suffix allomorphy for V-stems and C-stems

\begin{tabular}{|l|l|l|}
\hline verbal stem & $\begin{array}{l}\text { V-stem } \\
\text { e.g., tabe- 'eat' }\end{array}$ & $\begin{array}{l}\text { C-stem } \\
\text { e.g., nom- 'drink' }\end{array}$ \\
\hline a. present negative & $\ldots$..n-nai & ...C-anai \\
\hline b. plain present & $\ldots$ V-ru & ...C-u \\
\hline c. inchoative & $\ldots$ V-joo & ...C-oo \\
\hline d. conditional & $\ldots$ V-reba & ...C-eba \\
\hline e. causative & $\ldots$ V-sase- & ...C-ase- \\
\hline f. passive & $\ldots$ V-rare- & ...C-are- \\
\hline
\end{tabular}

\footnotetext{
${ }^{5}$ In traditional Japanese grammar, the corresponding terms are godan-katuyou五段活用 and itidan katuyou一段活用, respectively.
} 


\begin{tabular}{|l|l|l|}
\hline g. imperative & $\ldots$ V-ro & ,..C-e \\
\hline h. potential & $\ldots$ V-rare- & ... C-e- \\
\hline
\end{tabular}

Traditional treatments (e.g., Kuroda 1965 and McCawley 1968) approach suffixal allomorphy as a strictly phonological matter. The resulting analyses (using insertion rules or deletion rules) remain necessarily construction-specific and of limited generality and can in any case not be extended to cover either the whole scale suppletion seen in the imperative <-ro, -e $>((7) g)$ or the large divergence between the allomorphs seen in the potential <-rare, -e $>((7) \mathrm{h})$ in a natural way, but the latter two are just as much part of the overall picture as the more 'regular' cases ((7)a-f).

The alternative would be to regard all allomorphs as listed, together with specifications of their environments. In traditional phonological analysis, this is an unappealing choice since, by assimilating everything to the worst-case suppletion scenario (7)g, it means making no contact with the phonotactic generalizations so clearly visible in (7), leading to massive redundancy.

In OT, we can have the best of both worlds by avoiding both construction-specific rules and unenlightening listing of allomorph environments: The allomorphs are listed, but the choice between the allomorphs is phonologically conditioned and falls to the usual selection mechanism. The basis idea is illustrated in (8) for the plain present allomorphs $<-\mathrm{u},-\mathrm{ru}>$. Rather than specifying /-u/ as attaching to C-stems, and /-ru/ as attaching to V-stems, the allomorphs are both available to attach to both types of stems, and choosing either one fulfills faithfulness constraints. It is then up to the phonological markedness constraints to choose the allomorph phonotactically most appropriate for each environment. ${ }^{6}$ As seen in (8), ONSET and an appropriate version of CODACOND choose the vowel-initial allomorph as optimal for the consonant-final stems, and vice versa for the consonant-initial allomorph.

(8) Plain present allomorph selection

\begin{tabular}{|c|c|c|c|c|}
\hline 'write'; 'eat' & & CodaCond & Onset & Faith \\
\hline \multirow[t]{4}{*}{ a. $/ \mathrm{kak} / /<-\mathrm{u},-\mathrm{ru}>/$} & kak-u & & & \\
\hline & kak-ru & $*$ & & \\
\hline & kakI-ru & & & $*$ Dep \\
\hline & $\mathrm{ka} \varnothing$-ru & & & *Max \\
\hline \multirow[t]{3}{*}{ b. $<$ tabe $>, /<-$ u, - ru $>/$} & tabe-u & & $*$ & \\
\hline & tabe-ru & & & \\
\hline & tabØ-u & & & *Max \\
\hline
\end{tabular}

In a similar way, allomorph selection for (non-ranuki) potentials proceeds as in (9) (where we consider only candidates with the correct plain present allomorph).

\footnotetext{
${ }^{6}$ This way of treating phonologically controlled allomorph selection is proposed in Mester 1994 for Latin verbs and has been further developed in, among others, Tranel 1998 for the French definite article.
} 
(9) Potential allomorph selection

\begin{tabular}{|c|c|c|c|c|c|}
\hline & & & CodaCond & Onset & Faith \\
\hline \multirow[t]{4}{*}{ a. $/$ kak/ $/<$-rare, -e $>/ /<$-u, -ru $>/$} & 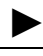 & kak-e-ru & & & \\
\hline & & kak-rare-ru & $*$ & & \\
\hline & & kakI-rare-ru & & & *Dep \\
\hline & & $\mathrm{ka} \varnothing$-rare-ru & & & *Max \\
\hline \multirow[t]{4}{*}{ b. $<$ tabe $>, /<$-rare, -e $>/ /<$-u, - ru $>/$} & $\nabla$ & tabe-rare-ru & & & \\
\hline & & tabe-e-ru & & $*$ & \\
\hline & & tabe-Te-ru & & & *Dep \\
\hline & & tab $\varnothing$-e-ru & & & *Max \\
\hline
\end{tabular}

\subsection{Ranuki variation in OT}

The particular ranuki variation of interest occurs in the potential suffix for V-verbs as exemplified above in (5). Despite being stigmatized by grammar mavericks as sloppy and lazy pronunciation, $r a$-less forms are abundantly observed in speech as well as in casual/informal writing. Ranuki is insightfully discussed by Gunji and Sakamoto 1999: 88-92 as an example of one of the ongoing changes in contemporary Japanese, and our understanding of the phenomenon has been considerably enhanced by the results of an undergraduate senior research project on casual speech contractions in Japanese conducted in Spring 2003 by the members of the UCSC undergraduate Japanese language research group (Ryan Tanaka, Eric Terao, Ember VanAllen, and Fujiko Yamamoto). Their Google web search (May 2003) resulted in 38,400 hits for ne-rare-ta and 52,300 hits for ne-re-ta. Similar numbers for many other verbs confirm the robust presence of the ranuki variation in contemporary Japanese, and the frequency of the often denigrated ranuki potentials with -re instead of -rare.

OT-treatments of variation and associated change have developed various ways of making the grammar generate further outputs besides the standard winners, whether by assuming that the ranking of constraints in an OT-grammar is only partial, such that certain pairs of constraints are not ranked with respect to each other and either order yields a valid competition (as in Nagy and Reynolds 1997, Antilla 1997, Ito and Mester 1997, and many other works, see Müller 1999 for general discussion), by having recourse to a more powerful stochastic notion of constraint ranking (Boersma 1997, Boersma and Hayes 2001), or by allowing direct (but limited) access in the evaluation to a rank-ordered set of non-optimal candidates (Coetsee 2004). The evidence considered here will not decide between these different theories of variation; for concreteness, we make use of a generic non-ranking format. For the ranuki case at hand, the crucial interaction is between the faithfulness constraint MAX-IO (protecting segments from being deleted) and a 'laziness' constraint that favors the $r a$-less form which we will here identity with a constraint ruling out sequences of $r$-initial syllables. An initial attempt at an analysis is depicted in (10). In order to simplify the tableau, we consider only candidates with the correct choice of allomorph (/-rare/ instead of /-e/, see (9)b). 
(10)

Variation for the potential form: [ne-rare-ta] $[$ ne-re-ta]
\begin{tabular}{|l|l|l:l|}
\hline & $\begin{array}{l}\text { /ne-rare-ta/ } \\
\text { 'sleep-potential-past' }\end{array}$ & (i) Max-IO (ii) *rVrV \\
\hline$>$ (i)»)(ii) & ne-rare-ta & & $*$ \\
\hline$>$ (ii)»>(i) & ne-re-ta & $* *$ & $*$ \\
\hline
\end{tabular}

The -rare form surfaces if the constraint * $\mathrm{rVrV}$ is ranked below the faithfulness constraint MAX, and the ra-less form wins if ranked above it. For consonant-final stems, the potential allomorph is $-e$, and there is no variation, since the constraint ${ }^{*} \mathrm{rVrV}$ is irrelevant here.

It might appear as if the variation can be captured in this way, but there is an immediate problem: There is no general phonological tendency in Japanese to reduce sequences of r-initial syllables, as illustrated with a sampling of words in (11).

Words with ...rVrV... sequences

\begin{tabular}{|l|l|l|l|}
\hline arare & 'hail, rice crackers' & raretu & 'enumeration' \\
\hline burari & 'casually, unexpectedly' & rarii & 'rally' \\
\hline gerira & 'guerrilla' & rireki & 'personal history' \\
\hline gururi & 'circumference' & ririsii & 'manly, valiant' \\
\hline hirari & 'quickly, nimbly' & riron & 'theory' \\
\hline honoruru & 'Honolulu' & roorerai & 'Lorelei' \\
\hline irori & 'hearth' & surari & 'easily, smoothly' \\
\hline karera & 'they' & suriru & 'thrill' \\
\hline kiriri & 'firmly, uprightly' & tororo & 'grated yam' \\
\hline moraru & 'morals' & turara & 'icicle' \\
\hline oriru & 'get off, go down' & uraraka & 'beautiful, calm' \\
\hline
\end{tabular}

These forms have no short variants and refute the idea that the ranking of * $\mathrm{rVrV}$ and Max is generally undetermined in the grammar of Japanese. Rather, faithfulness must outrank the markedness constraint. One might consider restricting ${ }^{*} \mathrm{rVrV}$ to verbal suffixes. Besides the fact that such a relativization of a markedness constraint to a particular morpheme class ${ }^{7}$ is not unproblematic, it remains ineffective because there is a passive suffix <-rare, -are > homophonous with the potential after V-stems (home-rare-ru 'be able to praise' or 'be praised', etc.) which has no ranuki variant -re (12). In fact, we will see below that the fact that there is no ranuki in passive turns out to hold a partial key to the solution. ${ }^{8}$

\footnotetext{
${ }^{7}$ And in particular, to affixes: see Albright 2004 for an argument that certain markedness constraints have root-specific variants, resulting in morpheme structure conditions on roots (as opposed to other forms).

${ }^{8}$ There is also no -re variant for the homophonous honorific ending (sensei-ga kaette ko-rareta/*ko-re-ta "the teacher returned-HONORIFIC").
} 
(12)
a.
sensei-ni yoku home $\left\{\begin{array}{c}\text { rare } \\ * \varnothing \text { re }\end{array}\right\}$-ta
teacher-DATIVE often praise-PASSIVE -PAST
'(He) was often praised by the teacher.'
b. kodomo-ni-wa

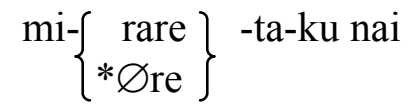
child-DATIVE-TOPIC
See-PASSIVE -VOLITIONAL-NEGATIVE
'(I) don't want to be seen by (my) children (in such a situation).'

The upshot is that ranuki only occurs in the potential form of $\mathrm{V}$-verbs, and can therefore not be attributed to a markedness constraint like $* \mathrm{rVrV}$, even when the latter is restricted to the verbal suffixes. A remaining last move of desperation, viz., restricting ${ }^{*} \mathrm{rVrV}$ to the potential suffixi.e., to a single morpheme - misses, besides its stipulative nature, an important systemic generalization. The sequence ...rare... itself is not the problem (as can be seen by the numerous words with $r V r V$ sequences in (11)), rather, there is a systemic reason for ranuki.

\subsection{Paradigm contrast}

Recall that the passive suffix is homophonous with the potential suffix (13)a, but ranuki creates a distinction between the potential and the passive forms, as illustrated in (13)b. ${ }^{9}$
a. standard: potential form: ...V-rare...
passive form: ...V-rare...
b. ranuki:
potential form: ...V-re...
passive form: ...V-rare...

Just as seen with the depalatalization effects illustrated in (3)-(4) above, ranuki is the result of a systemic (paradigmatic) constraint, this time, the morphological contrast constraint PARCONTRAST $^{10}(14)$ requiring overt phonological differences between the cells of the morphological paradigm of a given lexical item (see Kenstowicz 2002 for an earlier proposal along similar lines).

\section{(14) ParadigmContrast (PARCONTRAST)}

The cells of a paradigm are pair-wise phonologically distinct. Assign one mark for each pair of paradigm members that are not phonologically distinct.

\footnotetext{
${ }^{9}$ The potential -rare form is homonymous not just with the passive, but also with one kind of honorific (traditionally often understood as a special use of passive morphology), and it has been suggested that the homonymy of the potential with the honorific -rare might be, from a practical point of view, even more pernicious than the homonymy with the pure passive.

${ }^{10}$ In the interest of unifying the overall theory, PARCONTRAST could conceivably be interpreted as an instantiation of NOMERGE, here militating against phonologically identical realizations of two cells in the paradigm.
} 
We cannot simply substitute PARCONTRAST for *rVrV in conventional single-input OT tableaux such as in (10), because the potential form and the passive form, which derive from separate inputs, are each evaluated in separate tableaux. Like other systemic constraints, PARCONTRAST needs to evaluate and compare the output forms of both potential and passive forms in a single tableau. Previous work on output-output correspondence has developed a variety of mechanisms for such tasks (see Benua 1997, Burzio 1994, Ito and Mester 1997, Kenstowicz 1996, 1997, Steriade 1997, among others). We here follow McCarthy to appear in explicitly admitting whole paradigms as candidates - but with a focus on contrast, instead of uniformity and invariance. Tableau (15) illustrates the idea of the approach.

Contrast in paradigm selection

\begin{tabular}{|c|c|c|c|}
\hline & Candidate paradigms for /tabe-/ 'eat' & (i) Max-IO & (ii) ParContrast \\
\hline$>(\mathrm{i}) \gg(\mathrm{ii})$ & $\begin{array}{ll}\text { potential }<\text { rare }>: & \text { tabe-rare- } \\
\text { passive }<\text { rare }>: & \text { tabe-rare- } \\
\text { causative }<\text { sase }>: & \text { tabe-sase- } \\
\ldots & \ldots\end{array}$ & & $*$ \\
\hline$\nabla($ ii $) \gg($ i $)$ & $\begin{array}{ll}\text { potential }<\text { rare }>: & \text { tabe-re- } \\
\text { passive }<\text { rare }>: & \text { tabe-rare- } \\
\text { causative }<\text { sase }>: & \text { tabe-sase- } \\
\ldots & \ldots\end{array}$ & $* *$ & \\
\hline
\end{tabular}

In the first candidate paradigm (15)a, the potential and passive forms are identical, and hence violate PARCONTRAST, whereas in the second candidate paradigm (15)b, with the ra-dropped potential form, PARCONTRAST is fulfilled. Since PARCONTRAST is variably ranked with respect to Max-IO, both candidate paradigms are viable outputs for V-verbs.

Potential forms of C-stems (16), on the other hand, are predictably unaffected by the change. Their allomorph $-e$ is distinct from the passive suffix -are, hence, the fully faithful candidate paradigm fulfills PARCONTRAST, and harmonically bounds all other candidate paradigms. Since the fully-faithful candidate does not violate PARCONTRAST, reranking the two constraints makes no difference for the outcome. ${ }^{11}$

${ }^{11}$ A significant number of consonant-final stems end in [r] (e.g., wakar-u 'understand'), and they superficially resemble vowel-final stems with an r-initial suffix (e.g., tabe-ru). Some oft-cited minimal pairs are: $i-r u$ 'exist' vs. ir-u 'need', or ki-ru 'wear' vs. kir-u 'cut'. Such [r]-ending stems are common because there is an independent stem-forming -r- (kumo-r-u 'be cloudy' cf. kumo 'cloud', demo-r-u 'to do a demonstration', cf. demo 'demonstration', hamo-r-u 'harmonize', memo$r-u$ 'put in memo form', sabo-r-u 'to skip class', also in toma-r-u vs. tome-ru 'stop', intrans./trans. Therefore, another possible approach to ranuki is analogical leveling, namely, ranuki treats the V-verbs like r-ending C-Verbs ("metanalysis": cf. a napron > an apron, etc.). Thus, the vowelfinal tabe-ru 'eat-present' is reanalyzed as consonant-final taber-u, and the expected potential suffix would then be taber-e- instead of tabe-rare-. This kind of leveling would have to be very partial, however, because $\mathrm{V}$-Verbs are treated as $\mathrm{C}$-Verbs only in their potential forms, and remain $\mathrm{V}$-verbs in every other respect. For example, full reanalysis of taberu as a C-verb instead 
(16)

\begin{tabular}{|c|c|c|c|}
\hline & Candidate paradigm for /nom-/ 'drink' & Max-IO & ParContrast \\
\hline 1 & $\begin{array}{ll}\text { potential: } & \text { nom-e- } \\
\text { passive: } & \text { nom-are- } \\
\text { causative: } & \text { nom-ase- }\end{array}$ & & \\
\hline
\end{tabular}

From a diachronic perspective, and conjecturing that ranuki potentials with -re will ultimately replace the current potentials with -rare, the most likely course of the change in progress affecting the potentials of $\mathrm{V}$-stems in Japanese is as a four-stage process (17). ${ }^{12}$

\begin{tabular}{|l|l|}
\hline $\begin{array}{l}\text { Stage (i): } \\
\text { starting point }\end{array}$ & $\begin{array}{l}\text { the standard system without any ranuki variation (with fixed ranking of } \\
\text { MAX-IO » PARCONTRAST) }\end{array}$ \\
\hline $\begin{array}{l}\text { stage (ii): } \\
\text { variation }\end{array}$ & $\begin{array}{l}\text { the (current) system with variation, where PARCONTRAST is unranked with } \\
\text { respect to MAX-IO (MAX-IO, PARCONTRAST) }\end{array}$ \\
\hline $\begin{array}{l}\text { stage (iii): } \\
\text { reordered ranking }\end{array}$ & pure ranuki system (with fixed ranking of PARCONTRAST » MAX-IO) \\
\hline $\begin{array}{l}\text { stage (iv): } \\
\text { reanalysis of input }\end{array}$ & $\begin{array}{l}\text { pure ranuki system with reanalysis of input }<- \text {-rare }>\text { to }<- \text {-re>, where the } \\
\text { ranking between PARCONTRAST and MAX-IO becomes irrelevant. }\end{array}$ \\
\hline
\end{tabular}

of a V-verb predicts, against the actual facts, a conjugational paradigm with a $\mathrm{C}$-form negative *taber-anai instead of the $\mathrm{V}$-form tabenai 'does not eat', a C-form hortative *taber-oo instead of the V-form tabe-joo 'let us eat', etc.

${ }^{12}$ As a reviewer points out, it is unclear whether stages (iii) and (iv) are really separable. This would depend, for example, on the existence of speakers who start out at stage (ii) early in life and then move on to stage (iii) later, without a reanalysis of the input form of the potential suffix (which might come with the new generation). The standard conception of linguistic change in generative grammar since Kiparsky 1965 (see Sanders 2003 for a recent application in OT) assumes that the succession of grammars usually involves a stage like (iii) with adult grammars which have undergone change but no reanalysis of inputs. We have no reason to doubt its existence in principle, but have so far not investigated the facts that might bear on this question in the case here under discussion.

${ }^{13}$ It is important to note that what we are observing here is a requirement that the different members of a paradigm be distinct, not a general homonymy avoidance. PARCONTRAST applies only within the paradigm of a single lexical item and rules out the identity of two of its cells (here, potential and passive). It is not applicable across paradigms: there seems to be no homonymy avoidance between different lexical items. For example, the non-ranuki potential forms of /ki-/ 着る 'wear' and /kir-/ 切る 'cut' are different: ki-rare-ru 'can wear' vs. kir-e-ru 'can cut'. With ranuki, the two forms become segmentally identical: ki-re-ru 'can wear', kir-e-ru 'can cut'. The lack of homonymy avoidance even in dialects without a distinction between accented and unacented verbs (such as the city dialect of Fukuoka, see Smith 1999), where the two forms are also acceutually identical, shows that forms of different paradigms do not compete against each other in a single tableau. 
We now have in place a basic analysis of ranuki variation in the system of Japanese verbal derivation, where a floating systemic contrast PARCONTRAST interacts with the faithfulness constraint MAX-IO.

\section{Further Consequences: Allomorphy Correspondence}

The analysis so far raises two related questions regarding other competing candidate paradigms:

(i) Why does the potential suffix -rare change to -re, and not to any other phonological shape?

(ii) Why, instead of the potential suffix, doesn't the passive suffix -rare reduce to -re?

Question (i) calls attention to the fact that PARCONTRAST accounts for why some change occurs to differentiate the potential and the passive as members of the paradigm. However, it does not tell us what the resulting shape of the potential suffix should be. That is, why do we find ranuki (-rare $\rightarrow-r e$ ), and not re-dropping (-rare $\rightarrow-r a$ ), or a feature change (such as -rare $\rightarrow$ nare), all of which would satisfy PARCONTRAST? Some other plausible competing candidate paradigms that satisfy PARCONTRAST are listed in (18).

\begin{tabular}{|c|c|c|c|}
\hline & $\begin{array}{l}\text { Candidate paradigms for /tabe-/ 'eat' } \\
\text { that satisfy PARCONTRAST }\end{array}$ & $\begin{array}{l}\text { Max- } \\
\text { IO }\end{array}$ & Comments \\
\hline a. & $\begin{array}{ll}\text { potential }<\text { rare }>: & \text { tabe- } \text { re- } \\
\text { passive }<\text { rare }>: & \text { tabe-rare- } \\
\text { causative }<\text { sase }>: & \text { tabe-sase- } \\
\ldots & \ldots\end{array}$ & ** & Actual winning candidate paradigm. \\
\hline b. & $\begin{array}{ll}\text { potential }<\text { rare }>: & \text { tabe- } \text { nare- } \\
\text { passive }<\text { rare }>: & \text { tabe-rare- } \\
\text { causative }<\text { sase }>: & \text { tabe-sase- } \\
\ldots & \ldots\end{array}$ & & $\begin{array}{l}\text { No MAX-IO violations. The deletion } \\
\text { candidate (a) wins as long as some } \\
\text { suitable constraint, such as IDENT- } \\
\text { IO[nas], outranks MAX-IO. }\end{array}$ \\
\hline c. & $\begin{array}{l}\text { potential }<\text { rare }>\text { : } \\
\text { passive }<\text { rare }>\text { : } \\
\text { causative }<\text { sase }>\text { : } \\
\ldots\end{array}$ & $* *$ & $\begin{array}{l}\text { Same number of MAX-IO violations. } \\
\text { Constraint penalizing deletion at the } \\
\text { right-edge, such as ANCHOR-RIGHT. }\end{array}$ \\
\hline d. & $\begin{array}{ll}\text { potential }<\text { rare }>: & \text { tabe-_are- } \\
\text { passive }<\text { rare }>: & \text { tabe-rare- } \\
\text { causative }<\text { sase }>: & \text { tabe-sase- } \\
\ldots & \ldots\end{array}$ & * & $\begin{array}{l}\text { Less MAX-IO violations. ONSET must } \\
\text { be higher ranked than MAX-IO? }\end{array}$ \\
\hline
\end{tabular}

As noted in the Comments column, in order for the desired candidate paradigm (18)a $<$ tabe-re-, tabe-rare-, tabe-sase- $>$ to win, it becomes necessary not only to invoke another faithfulness constraints (18)c, but also to find the strategically correct rankings between faithfulness constraints (18)b and between faithfulness and markedness constraints (18)d. Unfortunately, it is unlikely that all the constraint rankings required to achieve this result are correct for the language at large. Thus ONSET cannot simply outrank MAX-IO, since there are many onsetless syllables in 
Japanese output forms. The other rankings are also difficult to justify from other parts of the grammar, which means that the learner would have to learn the ranking purely from the ranuki phenomenon - a fairly unlikely event. The ranking configuration $\{$ IDENT-IO[F], C $\}>>$ MAX-IO needed in (18) $\mathrm{b}$ (with $\mathrm{F}=[$ nas] and $\mathrm{C}=\mathrm{PARCONTRAST}$ ) is intrinsically problematic for at least some C, F: For example, $\{$ IDENT-IO[voi], *CODA $/[+$ voi, - son $]\}>>$ MAX-IO predicts wholescale deletion as a repair to avoid voiced coda obstruents, instead of voice neutralization - a pattern systematically unattested in languages (see Lombardi 2001, Steriade 2001, Pater 2003, and de Lacy 2003 for discussion and a variety of partial solutions).

Question (ii) is perhaps still more problematic. Even granted that all other constraints and necessary rankings are sorted out so that ra-deletion is the optimal repair, why does the change affect the potential and not the passive? Why is the optimal candidate paradigm the one with ranuki in the potential (19)a, and not the one with ranuki in the passive (19)b?

\begin{tabular}{|c|c|c|c|c|}
\hline & & & Max-IO & Comments \\
\hline a. & $\begin{array}{l}\text { potential }<\text { rare }>\text { : } \\
\text { passive }<\text { rare }>\text { : } \\
\text { causative }<\text { sase }>\text { : } \\
\ldots\end{array}$ & $\begin{array}{l}\text { tabe-re- } \\
\text { tabe-rare- } \\
\text { tabe-sase- }\end{array}$ & $* *$ & Actual winning candidate paradigm \\
\hline b. & $\begin{array}{l}\text { potential }<\text { rare }>\text { : } \\
\text { passive }<\text { rare }>\text { : } \\
\text { causative }<\text { sase }>\text { : } \\
\ldots\end{array}$ & $\begin{array}{l}\text { tabe-rare- } \\
\text { tabe-re- } \\
\text { tabe-sase- }\end{array}$ & ** & $\begin{array}{l}\text { passive ranuki: } \\
\text { Identical faithfulness and } \\
\text { markedness violations with winner. }\end{array}$ \\
\hline
\end{tabular}

The winner (19)a and the competing candidate (19)b have identical faithfulness and markedness violations, therefore appealing to some other constraint, or attempting to rerank some pair of constraints, cannot resolve the problem. One might take the bull by the horns and argue that the choice of (19)a instead of (19)b is a truly accidental outcome, things could just as well have been otherwise. We show below that this is not so.

Answers to both of the questions posed above are to be found not by scrutinizing the faithfulness and markedness profiles of individual verbal suffix allomorphs, but, pursuing the logic of the systemic constraints investigated here, by comparing the similarity relations between the allomorphs of the various suffixes given in (20) (repeated after (7) above). 
Suffix allomorphy for V-stems and C-stems

\begin{tabular}{|l|l|l|}
\hline verbal stem & $\begin{array}{l}\text { V-stem } \\
\text { e.g., tabe- 'eat' }\end{array}$ & $\begin{array}{l}\text { C-stem } \\
\text { e.g., nom-'drink' }\end{array}$ \\
\hline present negative & ...-nai & ...-anai \\
\hline plain present & ...-ru & ..-u \\
\hline inchoative & ...-joo & ...-oo \\
\hline imperative & ...-ro & ...-e \\
\hline conditional & ...-reba & ...-eba \\
\hline causative & ...-sase- & ...-ase- \\
\hline passive & ..-rare- & ...-are- \\
\hline potential & ..-rare- & ...-e- \\
\hline
\end{tabular}

This list of suffix allomorphs quickly reveals that, apart from the suppletive imperative <-ro/-e>, the usual shape variation is limited to a single segment: an initial consonant in $<-\mathrm{ru} /-\mathrm{u}>$, $<$-reba/-eba $>,<$-rare/-are $>$, <-sase/-ase $>,<$-joo/-oo $>$, or an initial vowel in $<$-anai/-nai $>$. The distance between the allomorphs of the potential $<$-rare, -e $>$, on the other hand, constitutes a much more significant divergence between the allomorphs.

This, we suggest, is the key to understanding why the potential suffix changes by ranuki from $<-$ rare, -e $>$ to $<$-re, -e $>$ and not to the other alternatives given in (18), and why it is the potential suffix and not the passive suffix that undergoes the change (see (19)): The actually observed change, as opposed to the alternatives mentioned, reduces the divergence between the allomorphs to a single segment, making them more similar to the usual case. In the next section, we implement this idea in a more formal way.

\subsection{Allomorph correspondence}

What we need is a precise way of measuring the distance between allomorphs that are exponents of the same morpheme, in order to be able to meaningfully compare different groups of associated allomorphs in terms of the degree of separation between the members, and compare different groups of this kind as candidates, each representing a different way of realizing a particular morpheme. In a general sense, this is the idea of "paradigm uniformity", but generalized so as to include both (inflectional) stem allomorphy (the usual domain of paradigm uniformity) and affix allomorphy.

Building on earlier proposals to limit variation within a paradigm (in particular, by Kenstowicz 1996, 1997), our most immediate model is McCarthy to appear ("Optimal Paradigms"), which is, however, limited to the shared stem (lexeme) in inflectional paradigms (cf. also the analysis of the affix-shape generalization in Tagalog in Kaufman 2003). We extend it here to a fully general correspondence constraint governing all kinds of allomorphs. As a first step (21), we postulate that for any two morphs allo ${ }_{1}$ and allo $_{2}$ that are exponents of the same morpheme, there is a correspondence relation between their segments (i.e., not mediated through some underlying form that they are associated with). 
(21) Allomorph correspondence relation $\mathrm{R}$

Let $m_{1}$ and $m_{2}$ be two morphs that stand in a relation of allomorphy, as co-exponents of one and the same morpheme $\mu$. Then there is a correspondence relation $\mathrm{R}$ between the segments of $m_{1}$ and the segments of $m_{2}$.

Using a simple schematic example for illustration, consider the set of allomorphs $<\tan$, an, ta, a $>$ in the array of forms (22).

$$
\begin{aligned}
& \text { mi- tan-u } \\
& \text { mep- } a n-\mathrm{u} \\
& \text { mi- ta- su } \\
& \text { mep- } a-\mathrm{su}
\end{aligned}
$$

A typical ${ }^{14}$ correspondence relation $\mathrm{R}$ holding between the members of $<t a n, a n, t a, a>$ is given in (23).

$\begin{array}{cccccc}\text { a. } & \text { b. } & \text { c. } & \text { d. } & \text { e. } & \text { f. } \\ \text { tan } & \text { tan } & \text { tan } & \text { an } & \text { an } & \text { t a } \\ \text { | } & \mid \text { | } & \mid & \mid & \mid & \mid \\ \text { an } & \text { ta } & \text { a } & \text { ta } & \text { a } & \text { a }\end{array}$

What we are interested in here is the overall similarity between these elements, not the extent to which they are each similar to some specific element, be it a classic underlying form or a designated member among the elements themselves (such as the most informative allomorph, as in the theory developed in Albright 2002).

The fact that there is no base-derivative priority in the relation we are studying here means, for example, that it is neither appropriate to reckon the non-corresponding $t$ in (23)a as a MAXviolation from the perspective of tan nor as a DEP-violation from the perspective of an. Rather than mechanically extending the MAX/DEP approach to this case of correspondence, and thereby implicitly declaring each form as some kind of quasi-base, which results in a doubling of penalties, as in McCarthy to appear, it seems more straightforward to recognize it for what it undeniably is - a flaw of the ordered pair $<\tan$, an $>$ as a member of the correspondence relation. In order to express this adequately, all we need is a type of segmental faithfulness that is more general than the standard variety, which is immediately individuated in terms of the MAX/DEP differentiation. Our proposal is stated in (24).

\section{Allomorph Correspondence Constraint (ALLOCORR)}

Let $\mathrm{R}$ be an allomorph correspondence relation between the segments of $m_{1}$ and those of $m_{2}$. Then one violation of ALLOCORR is incurred for each segment in $m_{1}$ or $m_{2}$ that is not included in R, i.e., has no correspondent in the other form.

\footnotetext{
${ }^{14}$ Here and in what follows, we simplify by taking only one-to-one (injective) relations into account, forgoing a distracting discussion of the formal machinery necessary to deal with fusions and splits.
} 
Other faithfulness constraints can be defined for the correspondence relation $\mathrm{R}$ in a parallel way, as illustrated in (25) for IDENT.

\section{ALLOIDENT[F]}

Let $\mathrm{R}$ be an allomorph correspondence relation $\mathrm{R}$ between the segments of $m_{1}$ and those of $m_{2}$. Then one violation of ALLOIDENT[F] is incurred for each pair of segments that stand in relation $\mathrm{R}$ to each other but differ in their value for $[\mathrm{F}]$.

Illustrating AlloCORR (24) using the earlier example (23), we have the results in (26), where the constraint violations are marked in the second row.

\begin{tabular}{|c|c|c|c|c|c|}
\hline $\begin{array}{l}\text { t a } \mathrm{n} \\
|| \\
\mathrm{a} n\end{array}$ & $\begin{array}{l}\text { ta n } \\
|| \\
\text { t a }\end{array}$ & $\begin{array}{c}\text { t a n } \\
\mid \\
\text { a }\end{array}$ & $\begin{array}{c}\mathrm{a} n \\
\mathrm{ta}\end{array}$ & $\begin{array}{l}\mathrm{a} n \\
\mathrm{a}\end{array}$ & $\begin{array}{r}\mathrm{t} a \\
\mathrm{a} \\
\mathrm{a}\end{array}$ \\
\hline$*$ & $*$ & $* *$ & * $\quad *$ & $*$ & $*$ \\
\hline
\end{tabular}

The Japanese verbal suffixes incur the ALLOCORR violations listed in (27).

\begin{tabular}{|lll|l|}
\hline & & & ALLOCORR violations \\
\hline present negative: & $<$-nai, & -anai $>$ & $*$ \\
\hline plain present: & $<$-ru, & -u> & $*$ \\
\hline inchoative: & $<$-joo, & -oo $>$ & $*$ \\
\hline causative: & $<$-sase-, & -ase-> & $*$ \\
\hline passive: & $<$-rare-, & -are-> & $*$ \\
\hline potential: & $<$-rare-, & -e-> & $* * *$ \\
\hline
\end{tabular}

For the plain present <-ru, $-\mathrm{u}>$, the vowel $u$ is shared between the two allomorphs (i.e., fulfills ALLOCORR), but the consonant $r$ only occurs in one of the allomorphs (i.e., does not have a correspondent in the other allomorph). For the present negative $<$-nai, -anai $>$, the three segments $n, a$, and $i$ fulfill ALLOCORR, but the initial $a$ lacks a correspondent. Important here is the fact that the potential has three violations of ALLOCORR for the segments rar. ${ }^{15}$

\subsection{AlloCorr and ParContrast}

Equipped with the allomorph correspondence constraints and the paradigm contrast constraint proposed earlier in section 3.3, we can start evaluating the optimality of various combinations. For this case, because we are evaluating the allomorphy variation, we need to evaluate a V-stem

${ }^{15}$ For the imperative suffix <-ro, -e>, it could be considered that there are also three violations of ALLOCORR, since none of the segments have an identical correspondent. Alternatively, if the vowels [o,e] are correspondents, there would be one ALLOCORR violation for the consonant [r], and ALLOIDENT violations for the lack of identity of the corresponding vowels. 
paradigm and a C-final stem paradigm in tandem. In order to simplify the display, the tableau in (28) limits itself to the potential and the passive, and furthermore shows only the suffix portion of the paradigm.

\begin{tabular}{|c|c|c|c|c|c|}
\hline & $\begin{array}{l}\text { potential: } \\
\text { passive: }\end{array}$ & $\begin{array}{l}\mid<\text {-e, } \quad \text {-rare }>1 \\
\mid<\text {-are, } \text {-rare }>/\end{array}$ & $\begin{array}{l}\text { (i) } \\
\text { Max-IO }\end{array}$ & $\begin{array}{l}\text { (ii) } \\
\text { ParContrast }\end{array}$ & (iii) \\
\hline $\begin{array}{l}\text { a. faithful candidate } \\
>\text { (i)»(ii) }\end{array}$ & $\begin{array}{l}\text { potential: } \\
\text { passive: }\end{array}$ & $\begin{array}{l}<\text {-e, } \quad \text {-rare }> \\
<\text {-are, } \text {-rare }>\end{array}$ & & $*$ & $* * *$ \\
\hline $\begin{array}{l}\text { b. ranuki (potential) } \\
\text { (ii)»(i) }\end{array}$ & $\begin{array}{l}\text { potential: } \\
\text { passive: }\end{array}$ & $\begin{array}{l}<\text {-e, } \quad \text {-re }> \\
<\text {-are, } \text {-rare }>\end{array}$ & $* *$ & & $*$ \\
\hline c. ranuki (passive) & $\begin{array}{l}\text { potential: } \\
\text { passive: } \\
\text {... }\end{array}$ & $\begin{array}{l}<\text {-e, } \quad \text {-rare }> \\
<\text {-are, } \quad \text {-re }>\end{array}$ & $* *$ & & $* * *$ \\
\hline
\end{tabular}

The faithful candidate (28)a violates PARCONTRAST because the potential and the passive overlap in the allomorph (-rare), and it shows four ALLOCORR violations (three for the potential, and one for the passive). As before (see (15)), the faithful candidate comes out as the winner in competitions where MAX-IO dominates PARCONTRAST. With the opposite ranking, one of the PARCONTRAST-fulfilling candidates (28)b,c is the winner. Among these two candidates, (28)(b) has ranuki in the potential, and (c) has ranuki in the passive, and this is where ALLOCORR is crucial. The ALLOCORR violations for (28)(b) are minimal: one in the potential <-e, -re>, and one in the passive $<$-are, -rare $>$. In (28)c, the ranuki passive $<$-are, -re $>$ also accrues one violation, just like $<$ are, -rare $>$ (the non-corresponding segment is now $a$ instead of $r$ ). The potential $<-\mathrm{e}$, -rare $>$, on the other hand, accrues two fatal ALLOCORR violations in addition to the one shared with $<-$ e, -re $>$. The paradigm with ranuki in the passive (28)(c) is therefore harmonically bounded by the paradigm with ranuki in the potential (28)(b), and will never be a winner.

Other PARCONTRAST-fulfilling candidates discussed earlier are also accounted for by the allomorphic correspondent constraints. In the "re-nuki" candidate (29)d, where re deletes rather than $r a$, the deletion of $r e$ leads to an additional ALLOIDENT violation since the corresponding vowels $e$ and $a$ are no longer identical. Changing a segmental feature to avoid a PARCONTRAST violation, as in (29)e, does not reduce the number of ALLOCORR violations, and in addition incurs an ALLOIDENT violation.

\begin{tabular}{|l|ll|l|}
\hline d. $r e-n u k i$ & $\begin{array}{l}\text { potential: } \\
\text { passive: }\end{array}$ & $<$-e, -rare, - rare $>$ & ALLOIDENT violation \\
$\ldots$ & & & \\
\hline e. feature change & $\begin{array}{l}\text { potential: } \\
\text { passive: }\end{array}$ & $<-$-e, -nare, -rare $>$ & IDENT-IO violation \\
& $\ldots$ & & \\
\hline
\end{tabular}




\section{Conclusion}

This paper makes the proposal that morphological systems are governed, among other things, by an interrelated pair of constraints: (i) the contrast constraint PARCONTRAST, which requires differences among the members of the paradigm, and (ii) the allomorphic correspondence constraint ALLOCORR, which requires similarity among the allomorphic instantiations of a morpheme. While many details and a number of fundamental questions remain to be settled, the analysis of the ranuki phenomenon in the system of verbal derivation in Japanese developed here as a test case shows that this contrast-based and intrinsically systemic pair of constraints allows us to make some progress towards unified explanations in morphology.

\section{References}

Albright, Adam (2002) The Identification of Bases in Morphological Paradigms. Doctoral dissertation. Department of Linguistics, UCLA.

Albright, Adam (2004) The emegence of the marked: root-domain markedness in Lakhota. Paper presented at the 2004 LSA Annual Meeting, Boston, Jan. 2004.

Antilla, Arto (1997) Deriving variation from grammar. In: Frans Hinskens, Roeland van Hout and W. Leo Wetzels (eds.), Variation, Change, andPhonological Theory, 35-68. Amsterdam: Benjamins.

Benua, Laura (1997) Transderivational Identity: Phonological Relations between Words. Doctoral dissertation, University of Massachusetts, Amherst.

Boersma, Paul (1997) How we learn variation, optionality, and probability. Proceedings of the Institute of Phonetic Sciences of the University of Amsterdam, 21:43-58.

Boersma, Paul and Hayes, Bruce (2001) Empirical Tests of the Gradual Learning Algorithm. Linguistic Inquiry, 32:45-86.

Burzio, Luigi (1994) Principles of English Stress. Cambridge, U.K.: Cambridge University Press.

Coetsee, Andries W. (2004) Variation as accessing non-optimal candidates: variable vowel deletion in Faialense Portuguese. Paper presented at the 2004 LSA Annual Meeting, Boston, Jan. 2004.

de Lacy, Paul (2003) Fixed ranking and the 'too many solutions' problem. Handout of talk delived at CASTL Kick-off Conference, Oct. 2003. University of Tromsø. Tromsø, Norway.

Flemming, Edward S. (1995) Auditory Representations in Phonology. Doctoral dissertation, UCLA.

Flemming, Edward S. (2002) Auditory Representations in Phonology. New York and London: Routledge.

Gunji, Takao and Sakamoto, Tsutomu (1999) Gengogaku-no hoohoo [Methods in Linguistics]: Introduction to Modern Linguistics. Tokyo: Iwanami Publishing.

Halle, Morris (1962) Phonology in generative grammar. Word, 18:54-72.

Ito, Junko and Mester, Armin (1997) Correspondence and compositionality: The ga-gyo variation in Japanese phonology. In: Iggy Roca (ed.), Derivations and Constraints in Phonology, 419-462. Oxford, U.K.: Oxford University Press. 
Ito, Junko and Mester, Armin (to appear) Systemic markedness and faithfulness. In, Proceedings of the 39th Meeting of the Chicago Linguistics Society. Chicago: Department of Linguistics, University of Chicago.

Kaufman, Daniel (2003) Paradigm effects and the affix-shape/position generalization. In: Gina Garding and Mimu Tsujimura (eds.), Proceedings of WCCFL 22, 273-286. Somerville, MA: Cascadilla Press.

Kenstowicz, Michael (1996) Base-identity and uniform exponence: alternatives to cyclicity. In: J. Durand and B. Laks (eds.), Current Trends in Phonology, 363-393. Salford, U.K.: European Studies Research Institute.

Kenstowicz, Michael (1997) Uniform exponence: exemplification and extension. In: Viola Miglio and Bruce Moreen (eds.), University of Maryland Working Papers in Linguistics 5. Selected Phonology Papers from Hopkins Optimality Theory Workshop 1997 / University of Maryland Mayfest 1997, 139-155.

Kenstowicz, Michael (2002) Paradigmatic uniformity and contrast. In: Anikó Csirmaz, Zhiqiang Li, Andrew Nevins, Olga Vaysman and Michael Wagner (eds.), Phonological Answers (and their Corresponding Questions). MIT Working Papers in Linguistics 42 (MITWPL 42). Cambridge, Mass.: Dept. of Linguistics and Philosophy, MIT.

Kiparsky, Paul (1965) Phonological Change. Doctoral dissertation, MIT.

Kuroda, Shige-Yuki (1965) Generative Grammatical Studies in the Japanese Language. Doctoral Dissertation, MIT.

Lombardi, Linda (2001) Why place and voice are different: constraint-specific alternations in Optimality Theory. In: Linda Lombardi (ed.), Segmental Phonology in Optimality Theory. Constraints and Representations, 13-45. Cambridge: Cambridge University Press.

McCarthy, John J. (to appear) Optimal paradigms. In: Laura Downing, Tracy Alan Hall and Renate Raffelsiefen (eds.), Paradigms in Phonological Theory. Oxford, U.K.: Oxford University Press.

McCarthy, John J. and Taub, Alison (1992) Review of C. Paradis and J.-F. Prunet, eds., The Special Status of Coronals: Internal and External Evidence. Phonology, 9:363-370.

McCawley, James D. (1968) The Phonological Component of a Grammar of Japanese. The Hague, The Netherlands: Mouton.

Mester, Armin (1994) The quantitative trochee in Latin. Natural Language and Linguistic Theory, 12:1-61.

Müller, Gereon (1999) Optionality in optimality-theoretic syntax. GLOT International, 4:3-8.

Nagy, Naomi and Reynolds, Bill (1997) Optimality Theory and variable word-final deletion in Faetar. Language Variation and Change, 9:37-55.

Padgett, Jaye (2003) Contrast and post-velar fronting in Russian. Natural Language and Linguistic Theory, 21:39-87.

Pater, Joe (2003) Balantak metathesis and theories of possible repair in Optimality Theory. Ms. UMass, Amherst. Amherst, MA.

Sanders, Nathan (2003) Opacity and Sound Change in the Polish Lexicon. Ph.D. dissertation. Department of Linguistics, UCSC.

Smith, Jennifer L. (1999) Noun Faithfulness and Accent in Fukuoka Japanese. In: Sonya Bird, Andrew Carnie, Jason D. Haugen and Peter Norquest (eds.), Proceedings of WCCFL XVIII, 519-531. Somerville, MA: Cascadilla Press.

Smolensky, Paul (1993) Harmony, markedness, and phonological activity. Handout from Rutgers Optimality Workshop I. New Brunswick, New Jersey. 
Steriade, Donca (1995) Underspecification and markedness. In: John Goldsmith (ed.), Handbook of Phonological Theory, 114-174. Cambridge, MA: Blackwell.

Steriade, Donca (1997) Lexical conservatism and its analysis. In: Linguistic Society of Korea (ed.), Linguistics in the Morning Calm. Selected Papers from SICOL 1997, 157-179. Seoul: Hanshin Publishing House.

Steriade, Donca (2001) The Phonology of Perceptibility Effects: the P-map and its consequences for constraint organization. (http://www.linguistics.ucla.edu/people/steriade/papers/Pmap for phonology.doc, 04/15/2004.)

Tranel, Bernard (1998) Suppletion and OT: on the issue of the syntax/phonology interaction. In: Emily Curtis, James Lyle and Gabriel Webster (eds.), Proceedings of the West Coast Conference on Formal Linguistics 16, 415-429.

Department of Linguistics

University of California, Santa Cruz

Santa Cruz, CA 95064

U.S.A.

ito@ucsc.edu

mester@ucsc.edu 